\title{
Cell Proliferation in Human Melanoma
}

\author{
S. Shirakawa, J. K. Luce, I. Tannock, and E. Frei III \\ From the Department of Developmental Therapeutics and the Department of \\ Experimental Radiotherapy, The University of Texas M. D. Anderson Hospital \\ and Tumor Institute, Houston, Texas 77025
}

\begin{abstract}
A в S T R A C T The cytokinetics of subcutaneous metastases in five patients with melanoma was studied. Multiple simultaneous biopsies following pulse labeling with tritiated thymidine were performed in one patient. There was relatively uniform labeling and mitotic indices among these. Within the individual tumors, there was some variation in the labeling index with small clusters of tumor cells having significantly higher labeling indices than more sparsely infiltrating tumor cells. Repetitive biopsies following pulse labeling were performed in two patients. The per cent labeled mitosis curves were similar in the two patients. By computer analysis a median $\mathrm{G}_{2}$ period of $5.3 \mathrm{hr}$ and an $\mathrm{S}$ period of $21 \mathrm{hr}$ were obtained. The generation time $\left(T_{c}\right)$ was highly variable with a median of 3 days. This $T_{c}$ was consistent with that calculated from grain count studies in these patients. Two patients received either intermittent or continuous tritiated thymidine over a 10-20 day period. Analysis of the labeling index curve by computer fitting indicated a growth fraction of $20-30 \%$. The growth fraction calculated by other indirect methods was consistent with the computer analysis. The potential tumor doubling time as calculated from the $T_{c}$ and growth fraction was much shorter than the actual doubling time indicating that cell loss was approximately $70 \%$ of the rate of cell production.
\end{abstract}

\section{INTRODUCTION}

Since the introduction of tritiated thymidine $\left(\mathrm{TdR}^{-3} \mathrm{H}\right)$, a precursor specific for DNA and highly suitable for autoradiography (1), cytokinetic research of experimental tumors and human leukemia has developed rapidly. However, studies of human solid tumors have been limited (2-9).

Dr. Tannock is a recipient of a Rosalie B. Hite Postdoctoral Fellowship and a Research Training Fellowship of the International Agency for Research on Cancer.

Received for publication 11 November 1969 and in revised form 15 January 1970.
In addition to fundamental knowledge concerning tumor growth such studies provide important information for therapeutic trials. Anti-tumor agents may be divided into those that affect proliferating cells exclusively, and those which affect both proliferating and nonproliferating cells $(10,11)$. Thus, the choice of agents or combination of agents, the duration of administration, the interval between courses (scheduling), the total duration of treatment, and the interpretation of the magnitude and duration of response should ideally be predicted on the basis of cytokinetic information with respect to the tumor as well as normal rapidly proliferating tissues $(12,13)$. Therapeutic approaches based on cytokinetic information have improved the therapeutic index of anti-tumor agents in experimental systems (14, 15). Human metastatic melanoma is ideally suited for cytokinetic studies because: (a) metastatic nodules commonly occur in the subcutaneous tissue and can be readily biopsied, and $(b)$ such tumors are medullary, that is, they have a high proportion of neoplastic cells in the stroma.

The present study describes the proliferative behavior of tumor cells in five patients with disseminated melanoma who had multiple small subcutaneous melanoma metastases. The cell cycle times, the phases of the mitotic cycle, the growth fraction, and the rate of cell loss were determined.

\section{METHODS}

Five patients with multiple subcutaneous metastatic melanoma were selected. The cytokinetic studies were performed immediately before treatment with the new agent dimethylimidazole carboxamide triazeno which has produced objective response in $25 \%$ of patients with metastatic melanoma (16). The nature and purpose of the study was discussed with the patients and informed consent was obtained.

The first patient, C. B., a $66 \mathrm{yr}$ old female, was given a single injection of $8.5 \mathrm{mCi}$ of methyl-thymidine- ${ }^{3} \mathrm{H}$, SA 15.5 $\mathrm{Ci} /$ mmole (Schwartz Bioresearch Inc., Orangeburg, N. Y.). The second patient, L. L., a 70 yr old female, and the third patient, E. H., a $37 \mathrm{yr}$ old male, were given $10 \mathrm{mCi}$ of TdR- ${ }^{8} \mathrm{H}$ intravenously. The fourth patient, T. J., a $77 \mathrm{yr}$ old 


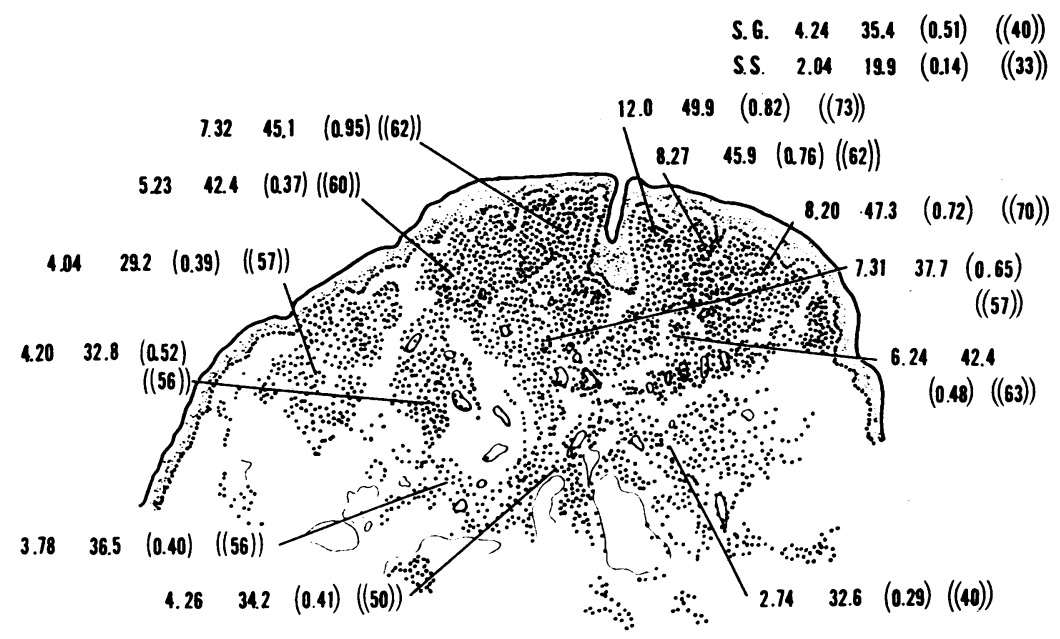

Figure 1 Labeling index, mean grain count, (mitotic index), ( $\%$ labeled mitosis)) (C. B.), [B], size of tumor $3.0 \times 1.7 \mathrm{~mm}$.

male, was given $3 \mathrm{mCi}$ intravenously every $24 \mathrm{hr}$ for 10 days with a total dose of $30 \mathrm{mCi}$. The fifth patient, M. S., a 49 yr old female, received $3 \mathrm{mCi} / 24 \mathrm{hr}$ by continuous intravenous infusion for 20 days (total dose $60 \mathrm{mCi}$ ). ${ }^{1}$ After the injection of $\mathrm{TdR}-{ }^{3} \mathrm{H}$, tissue specimens were obtained by excisional biopsy from small subcutaneous metastatic lesions. For lesions greater than $1 \mathrm{~cm}$ in diameter tumor was obtained by aspiration biopsy employing a special needle.

Autoradiography. The specimens were fixed with $6 \%$ formaldehyde in $0.1 \mathrm{M}$ phosphate buffer $(\mathrm{pH} \mathrm{7.4)}$ with $8 \%$ sucrose, embedded in paraffin, and sectioned at $5 \mu$. For radioautography, the slides were mounted with Kodak AR10 films by the stripping technique (17). The mounted slides were exposed for either $30-45$ days after pulse labeling or 2-3 months after intermittent and continuous labeling at $4^{\circ} \mathrm{C}$

${ }^{1}$ The use of the isotope in patients in this study was approved by the Isotope Committee of the University of Texas M. D. Anderson Hospital and Tumor Institute under license from the Department of Public Health, State of Texas. in light-tight boxes containing Drierite (W. A. Hammond Co., Xenia, Ohio). The slides were developed in Kodak D19 Developer at $18^{\circ} \mathrm{C}$, fixed in Kodak acid fixer, and stained with hematoxylin-eosin stains. From each paraffin block at least 10 slides were prepared. The labeling index, grain counts, mitotic index, and labeled mitoses were determined on only those cells which could be recognized as neoplastic with reasonable certainty. The average background was less than one grain per cell nucleus, and a labeling criterion of three grains per cell was adopted. For each tumor area (Fig. 1) 1000-2000 melanoma cells were evaluated for labeling index, mitotic index, grain count, and per cent labeled mitoses. For each tumor (Table I) 6000 13,000 cells were analyzed.

Determination of DNA specific activity. DNA was isolated from about 30 to $50 \mathrm{mg}$ of fresh tumor specimens by the modified Schmidt-Thannhauser procedure (18). The DNA content was measured by the modified Dische's method (19). The specific activity of DNA was expressed as disintegration per minute $(\mathrm{dpm})$ at $100 \%$ efficiency per $\mu \mathrm{g}$ DNA.

TABLE I

Proliferation Activity of Melanoma and Benign Nevus (Patient C. B.)

\begin{tabular}{cccccccc}
\hline Samples & & $\begin{array}{c}\text { Size of } \\
\text { tumor }\end{array}$ & $\begin{array}{c}\text { No. of cells } \\
\text { examined }\end{array}$ & $\begin{array}{c}\text { Labeling } \\
\text { index }\end{array}$ & $\begin{array}{c}\text { Mean grain } \\
\text { counts }\end{array}$ & $\begin{array}{c}\text { Mitotic } \\
\text { index }\end{array}$ & $\begin{array}{c}\text { Labeled } \\
\text { mitoses }\end{array}$ \\
\hline \multirow{2}{*}{ Melanoma† } & $\mathrm{A}$ & $(\mathrm{mm})^{*}$ & & $\%$ & & $\%$ & $\%$ \\
& $\mathrm{~B}$ & $3.5 \times 1.2$ & 6,320 & 4.47 & 32.6 & 0.43 & 63 \\
& $\mathrm{C}$ & $1.8 \times 1.3$ & 13,438 & 6.11 & 34.1 & 0.59 & 59 \\
& $\mathrm{D}$ & $2.0 \times 1.2$ & 9,135 & 6.22 & 42.3 & 0.59 & 62 \\
Benign nevus & $\mathrm{E}$ & $1.5 \times 0.7$ & 4,015 & 3.83 & 31.9 & 0.49 & 54 \\
\hline
\end{tabular}

* Estimated from cross section.

$\dagger \mathrm{A}, \mathrm{C}$, and $\mathrm{D}$; intensely melanotic, B; slightly melanotic. 


\section{RESULTS}

Proliferative activity of different metastatic lesions and benign nevus. In patient C. B., four metastatic melanomatous lesions and one benign nevus were biopsied from different cutaneous sites $12 \mathrm{hr}$ after pulse labeling in order to determine the variation in proliferative behavior. One of these tumors ( $B$ in Table $I$ ) is presented schematically in Fig. 1. In this lesion and in the other metastases, the labeling indices in different areas ranged from 3 to $12 \%$. Nests of melanoma cells had a higher labeling index $(6.0-12.0 \%)$ than the infiltrating areas $(2.5-4.2 \%)$. The mitotic index paralleled the labeling index. The mean grain count was less variable, but also tended to vary with the labeling index.
The parameters of cellular proliferative activity for these tumors are presented in Table I. Although there was some variance of proliferative activity in different histological sites within a given metastatic lesion, the over-all variation in labeling index among the tumors was small $(3.83-6.22 \%)$. There was no difference between the intensely melanotic and the relatively amelanotic lesion. The benign nevus had a much lower labeling index $(0.34 \%)$.

Average duration of cell cycle as measured by labeled mitosis curve and grain count halving. Since the kinetic behavior of small tumors within a given patient did not vary greatly, serial biopsies of small lesions were performed in two patients (L. L. and E. H.) after pulse

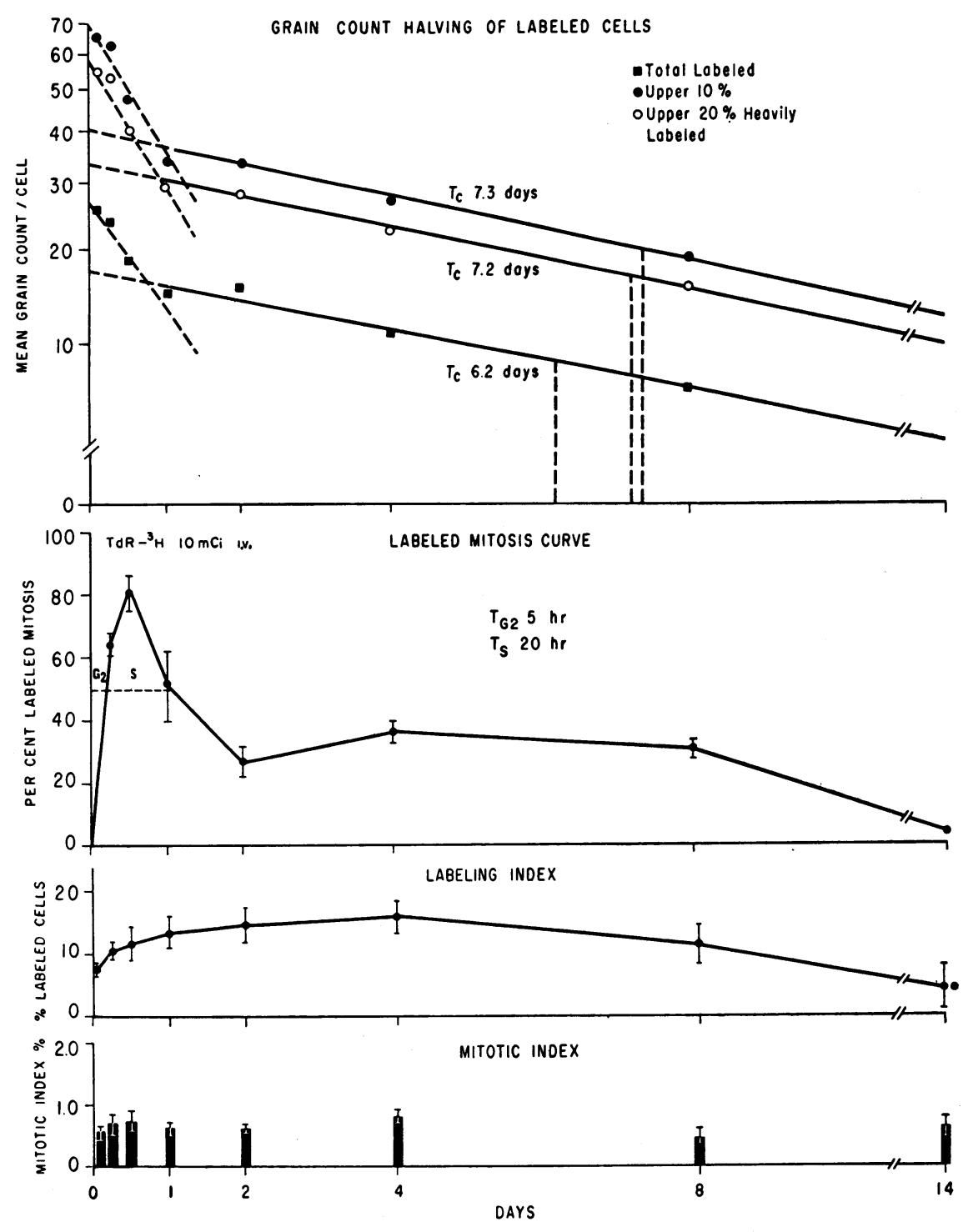

FIGURE 2 Cytokinetic studies in patient L. L. after pulse labeling with TdR- ${ }^{8} \mathrm{H}$. 


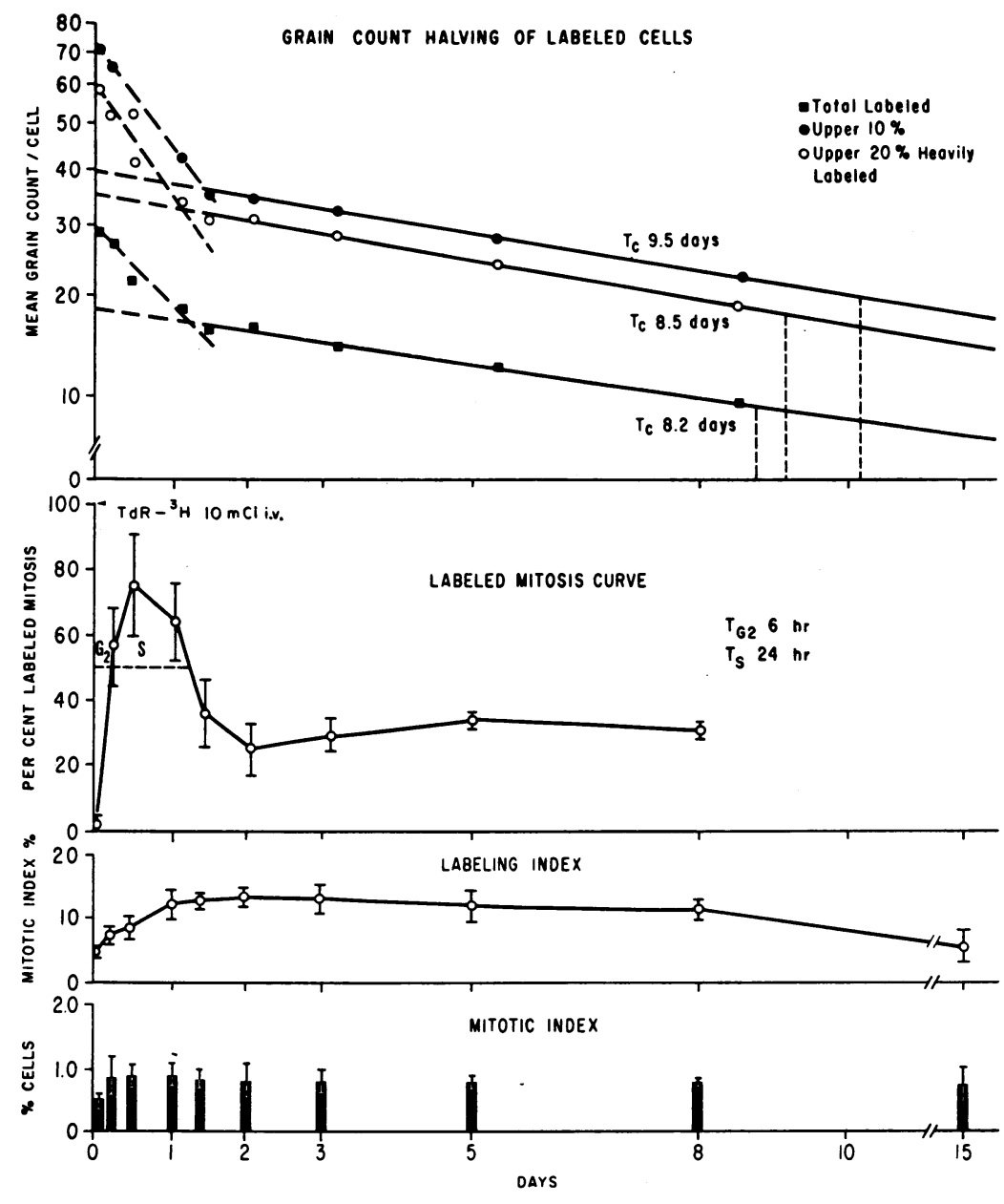

Figure 3 Cytokinetic studies in patient E. H. after pulse labeling with TdR- ${ }^{3} \mathrm{H}$.

labeling. Cell kinetic analyses were performed by the labeled mitosis technique $(20-22)$ and by grain count halving $(6,21,23)$. The percentage of labeled mitoses was plotted against time after a single injection of TdR- ${ }^{3} \mathrm{H}$ (Figs. 2 and 3 ). The time at which $50 \%$ of mitoses were labeled gives an approximate estimate of the mean duration of the premitotic phase $\left(\mathrm{T}_{\mathrm{a} 2}\right)$. The mean duration of DNA synthesis $\left(\mathrm{T}_{\mathbf{s}}\right)$ can likewise be approximated by the time between the $50 \%$ labeled mitosis on the ascending and descending portions of the curve. Using this method, the $\mathrm{T}_{\mathrm{a} 2}$ was about $5 \mathrm{hr}$ in the case of L. L. and $6 \mathrm{hr}$ in the case of E. H., and $T_{\mathrm{s}}$ was about $20 \mathrm{hr}$ in the case of L. L. and $24 \mathrm{hr}$ in the case of E. H. However, the labeled mitoses results are not significantly different for the two patients, and a single curve was computed to both sets of data by the method of Barrett (24). This method allows calculation of the mean phase durations and their standard deviations, and computes the probable distribution of cell-cycle times. This data is shown in Fig. 4; the median $\mathrm{T}_{\mathrm{c}}$ was about 3 days, and varied considerably.

The grain count usually decreases exponentially with time and the grain count half-time has been employed to measure the $T_{c}$ for relatively homogeneous populations of cells, all of which are in the proliferating pool (6, $21,23)$. The mean grain counts per cell were plotted in the semilogarithmic scale against time (Figs. 2 and 3 ). There were two components in the grain count curve. In the initial component the grain count decreased rapidly because the half-time of the first division is equal to the duration of $S$ or a portion thereof plus $G_{2}$ plus the moles per liter $(6,21)$. The first component had the half decay of about 1-1.5 days which is quite close to average duration of $T_{s}$ plus $T_{62}$. The second component of the curve had a half-time of 7 days for patient L. L. and 9 days for patient E. H. There was good agreement 


\section{COMPUTED LABELED mitoses CURVE}
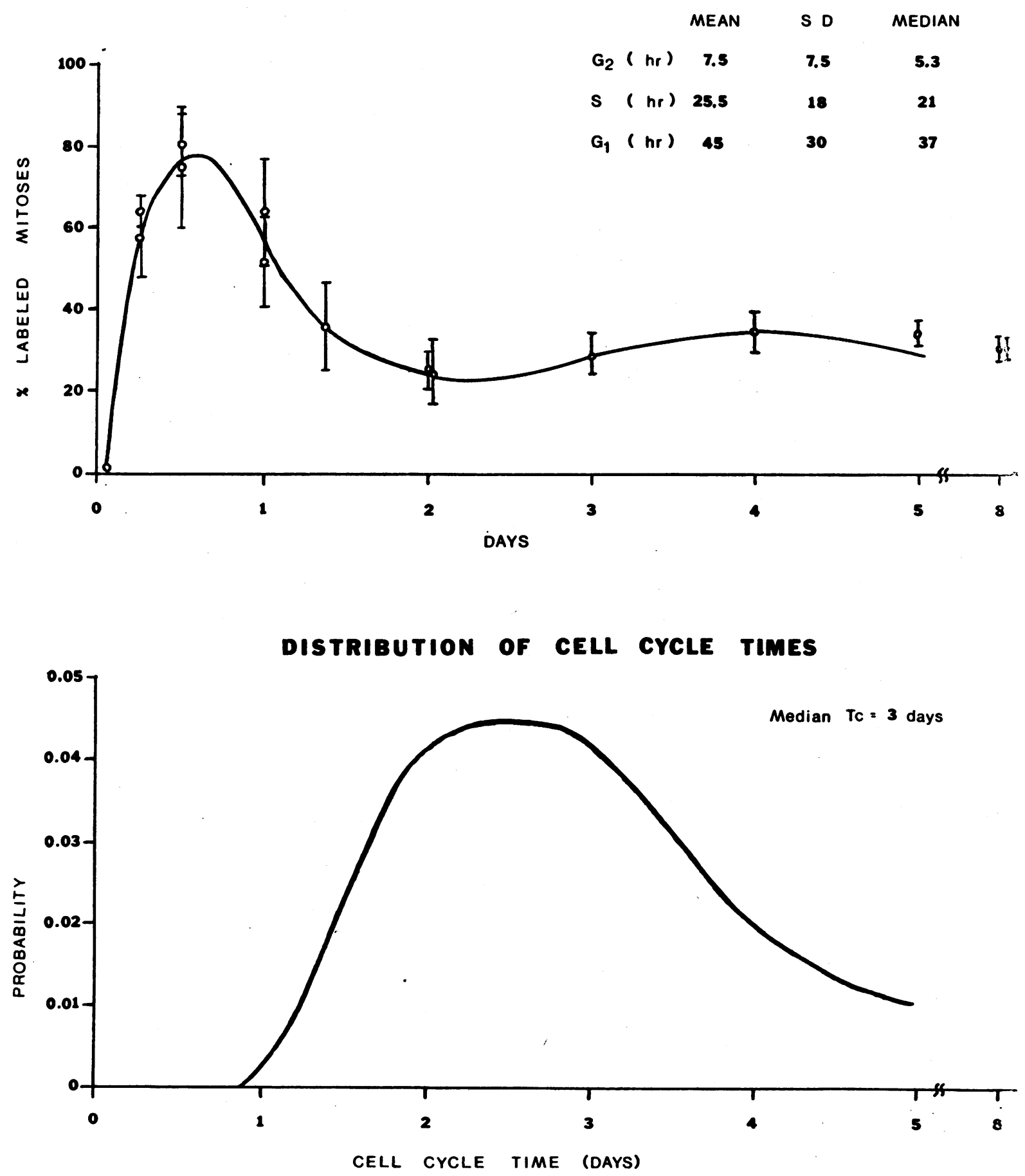

Figure 4 Computed labeled mitoses curve. 
between the half times as determined from the upper $10 \%$ and upper $20 \%$, and from all of the labeled cells (see Discussion for interpretation).

The sequential labeling index and mitotic index, for patients L. L. and E. H. are also presented in Figs. 2 and 3. The labeling index increased during the first 24 $\mathrm{hr}$ as the cells labeled during the $\mathrm{S}$ period proceeded through division. It remained constant for the next 4-8 days suggesting equilibrium between labeled and nonlabeled cells. After 5-9 days, the labeling index decreased as the grain counts were diluted below the threshold level. In both patients, the mitotic index did not change, indicating that the samples obtained from different lesions had a reasonably similar proliferative
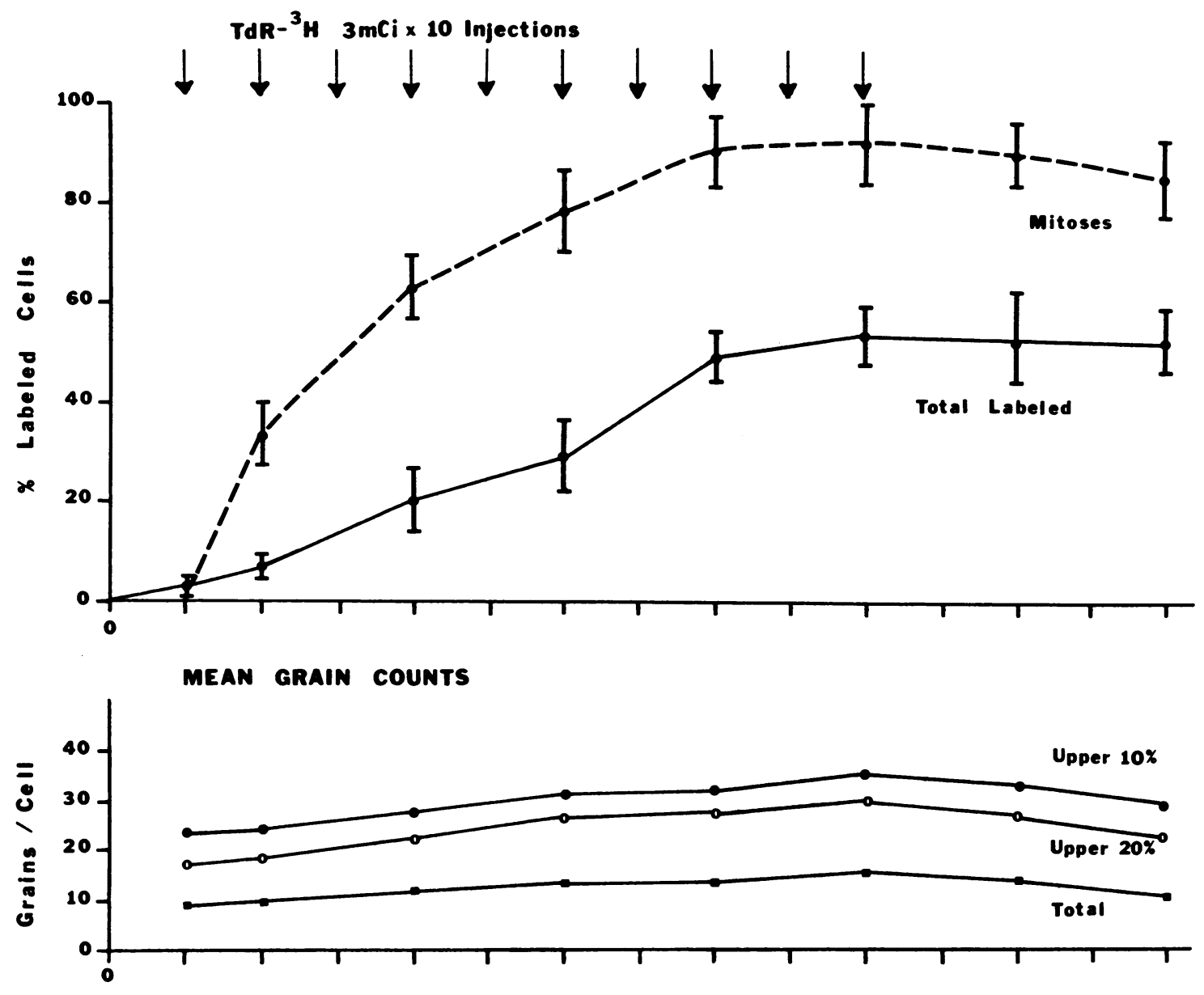

MITOTIC INDEX

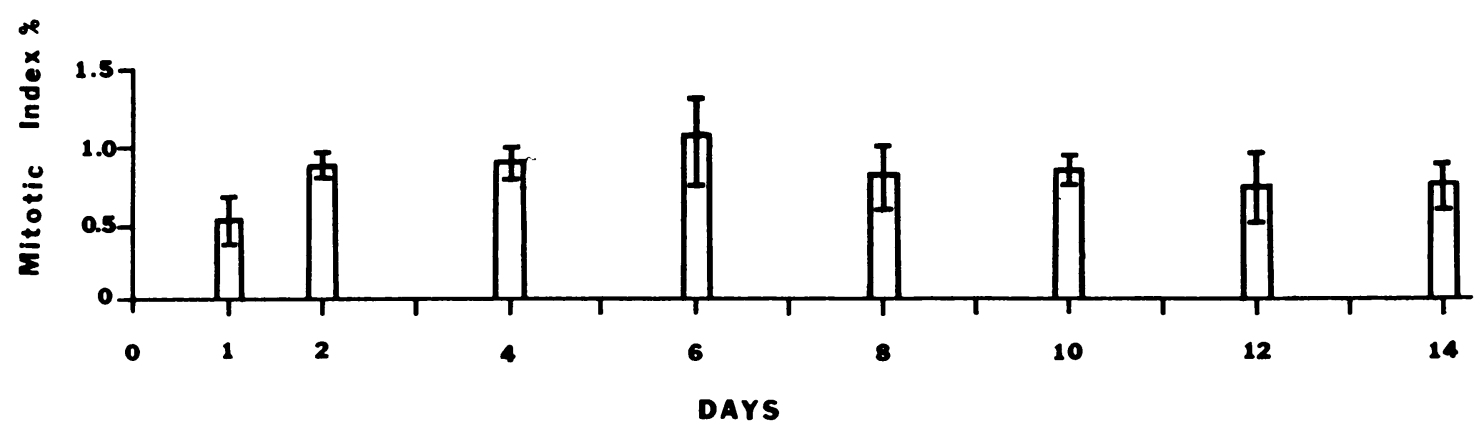

FIGURE 5 Cytokinetic studies in patient T. J. intermittent labeling with TdR- ${ }^{3} \mathrm{H}$. 

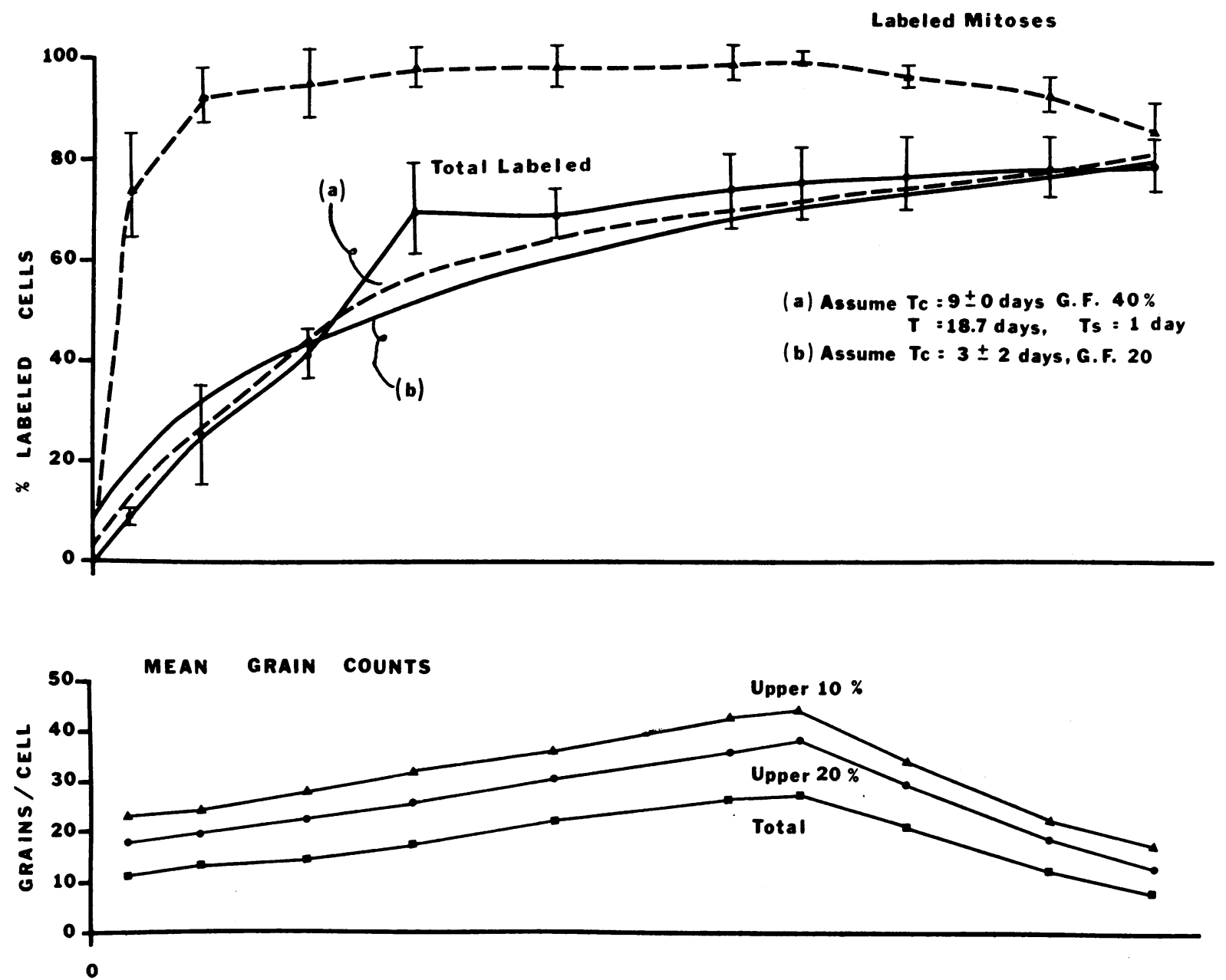

MITOTIC INDEX

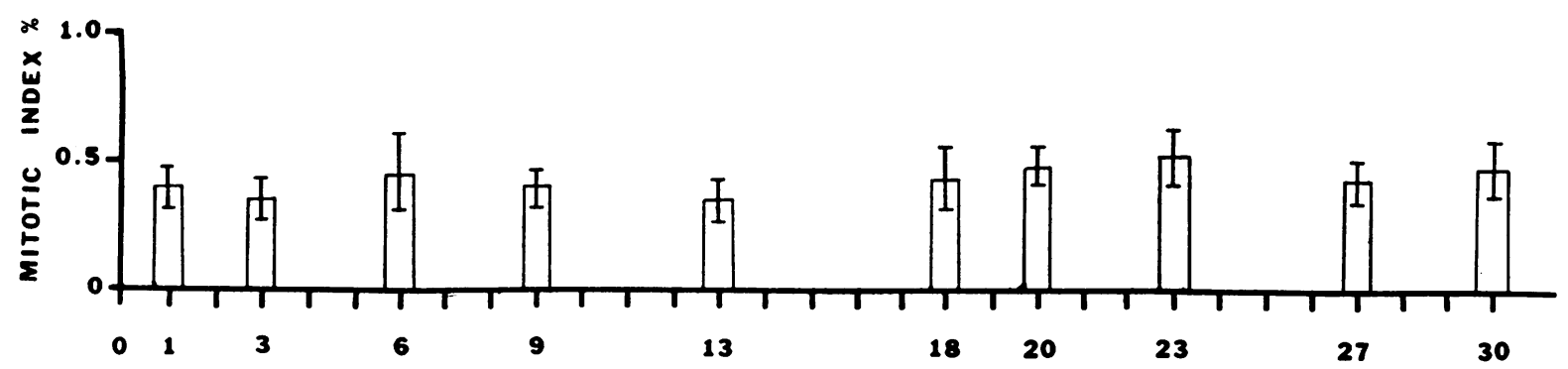

DA.YS

FIgURE 6 Cytokinetic studies in patient M. S., continuous labeling with $T d R-{ }^{8} \mathrm{H}$. In the upper figure curve $\mathrm{A}$ was derived by assuming that cell cycle phase durations are constant with $\mathrm{T}$. $=1$ day, $T_{c}=9$ days, $G F=40 \%$. Curve $B$ was derived for the distributions of cell cycle phase durations corresponding to the computed labeled mitoses curve of Figure 7 (Steel et al., 28). Parameter values were $\mathrm{T}_{\mathrm{s}}=25.5 \pm 18 \mathrm{hr}, \mathrm{T}_{\mathrm{c}}=3 \pm 2$ days, $\mathrm{GF}=20 \%$. Either curve is an acceptable fit to the experimental points. 
TABLE II

Influence of Previous Biopsy and Size of Tumor on Proliferative Activity of Melanoma Cells

\begin{tabular}{lcccc}
\hline Patient & Size of tumor & Site in tumor & Labeling index & Mitotic index \\
\hline T. J. & $0.4 \times 0.5 \mathrm{~mm}$ & - & $\%$ & $\%$ \\
& $3 \times 4 \mathrm{~cm}$ & Adjacent to & $49.3 \pm 3.4$ & $0.75 \pm 0.12$ \\
& & previous biopsy & $59.5 \pm 8.2$ & $1.10 \pm 0.46$ \\
& & Intact areas & & \\
& & Periphery & $48.1 \pm 7.9$ & $0.72 \pm 0.31$ \\
& & Center & $32.1 \pm 4.8$ & $0.36 \pm 0.16$ \\
M. S. & $0.4 \times 0.4 \mathrm{~mm}$ & - & $70.2 \pm 4.4$ & $0.48 \pm 0.08$ \\
& $2 \times 3 \mathrm{~cm}$ & Periphery & $68.2 \pm 8.4$ & $0.51 \pm 0.16$ \\
& & Center & $45.0 \pm 9.6$ & $0.38 \pm 0.22$ \\
\hline
\end{tabular}

The tumors were obtained 4 days after a 10 day intermittent tritiated thymidine injection in patient T. J. and on the last day of a 20 day continuous infusion in patient M. S. Each value represents the mean $\pm \mathrm{SD}$ of three determinations.

activity and that the doses of $\mathrm{TdR}-{ }^{8} \mathrm{H}$ used did not cause radiation injury sufficient to alter the cytokinetics.

Intermittent and continuous labeling. The fourth patient, T. J., was given $3 \mathrm{mCi}$ every $24 \mathrm{hr}$ for 10 days. Serial biopsies of small subcutaneous metastases were performed at the intervals listed. The labeling index increased linearly for 8 days, the rate of increase decreased between the 8 th and 10th days, and thereafter, leveled off (Fig. 5). However, the rate of increase in per cent labeled mitoses was relatively slow indicating that the interval between $\mathrm{TdR}-{ }^{8} \mathrm{H}$ injections was too long and allowed unlabeled cells to enter mitosis.

The fifth patient, M. S., received TdR- ${ }^{3} \mathrm{H}$ by continuous intravenous infusion at a dose of $3 \mathrm{mCi} / 24 \mathrm{hr}$ for 20 days (Fig. 6). The labeling index increased to $70 \%$ by the 9th day and then increased more slowly. The per cent labeled mitoses increased rapidly reaching $75 \%$ after 1 day and greater than $90 \%$ after the 3rd day. After termination of continuous labeling the labeled mitoses decreased considerably while the total per cent labeled cells did not change. The mean grain count increased twofold over the 20 day labeling period. The mitotic index remained constant within a range of 0.350.53 . After termination of continuous labeling, the mean grain count decreased exponentially with a half-time of 6.5 days (Fig. 5).

The above data was obtained from small $(<1 \mathrm{~cm}$ diameter) subcutaneous tumors. On the last day of TdR- ${ }^{3} \mathrm{H}$ infusion in patients T. J. and M. S. a larger tumor was also excised (Table II). These had labeling indices at the periphery similar to the simultaneously biopsied smaller tumor. The labeling index in the central areas of the larger tumors was less. There was no microscopic evidence of necrosis.
Decay of DNA specific activity. After TdR-- ${ }^{3} \mathrm{H}$ labeling, the DNA specific activity (dpm/ $\mu \mathrm{g}$ DNA) was measured serially on the samples obtained from three patients, L. L., E. H., and M. S. When the specific activities (dpm/ng DNA) were normalized by setting the initial highest value at $100 \%$ and plotted against time in a semilogarithmic scale, the DNA specific activity decreased exponentially with the half-decay time of 8-10 days (Fig. 7).

\section{DISCUSSION}

Our initial studies were designed to determine the variability of the proliferative activity of melanoma metas-

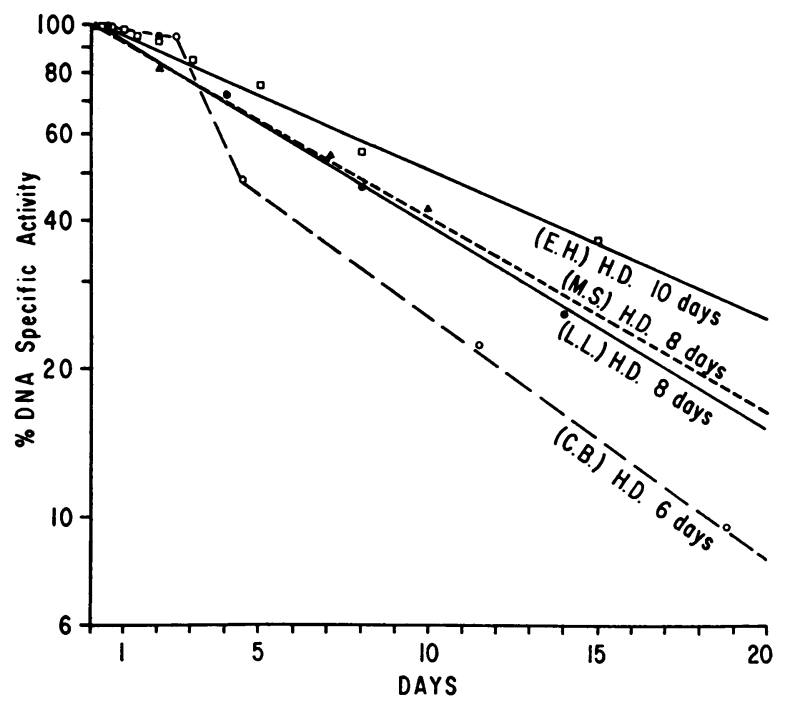

FIGURE 7 Decay of DNA specific activity.

Cell Proliferation in Human Melanoma 
tases within the same patient. Such variables included the character of the infiltrate, the size of the lesion, the center as compared to the periphery of the lesion, degree of melanotic pigmentation, and the effect of previous biopsies. The labeling index in different parts of small subcutaneous metastases varied from 3 to $12 \%$ (Fig. 1). In general, the small nests of tumor cells had higher labeling indices than the diffusely infiltrating tumor cells. These latter areas showed variable round cell chronic inflammatory infiltration. Thus, the lower proliferative activity may reflect host-defense mechanisms. It has been demonstrated in experimental systems that immune response to a tumor will restrain its proliferative activity $(25,26)$. In spite of the variation in the labeling index and mitotic index within different areas of small tumors, the labeling index and mitotic index of pooled random areas within small tumors in the same patient did not show a large variation (Table I). Such reproducibility is also apparent in the sequential biopsy studies. Most of the biopsies were performed on small subcutaneous tissues (less than $1 \mathrm{~cm}$ in diameter). Two simultaneous excisional biopsies of a large and small tumor were performed on two patients (T. J. and M. S.) who had continuous or intermittent labeling (Table II). In each instance, the labeling index and mitotic index in the center of the tumor was one-third less than at the periphery of the tumor. In neither instance was there morphologic evidence for necrosis in the center of the tumor. The periphery of the large tumors had labeling and mitotic indices comparable to those of small tumors. Frindel, Malaise, and Tubiana have observed that biopsy of a large tumor may not affect the labeling index of subsequent biopsies on the opposite site of the tumor in a labeled mitosis study (8). One of our patients (T. J.) had an excisional biopsy of a large tumor 10 days after a needle biopsy (Table II). The labeling and mitotic indices in areas immediately adjacent to the previous biopsy were slightly higher than in a remote peripheral area of the tumor.

In patient $\mathrm{C}$. B., where four small tumors were biopsied simultaneously after pulse labeling, three were intensely melanotic and one was minimally melanotic by gross and microscopic study. In spite of this, there was no significant difference in proliferative activity. This does not accord with the evidence that amelanotic lesions are more "malignant" in terms of clinical behavior (27).

Since at least within small tumors, the proliferative activity did not vary greatly within the same patient, serial biopsies were performed with pulse labeling and continuous labeling in patients with multiple small subcutaneous lesions in an effort to define the proliferative characteristics of the disease.

The per cent labeled mitosis curve following pulse labeling in patients L. L. and E. H. is plotted in Fig. 4.
The data were subjected to computer analysis (Fig. 4) and the median and standard deviation of the $\mathrm{T}_{\mathrm{s}}$ and $T_{G 2}$ determined (24). The value for $T_{G 2}$ (median $5.3 \mathrm{hr}$ ) is similar to that reported for human epidermoid carcinoma cells in serous effusions and in skin tumors $(6,8)$. The $\mathrm{T}_{\mathrm{s}}$ period (median $21 \mathrm{hr}$ ) is somewhat longer than has been observed or assumed from most previous clinical studies $(2-5,8,9)$. It is consistent with observations on neoplastic cells in serous effusions in man (6). The median $T_{a 1}$ period $\left(T_{c}\right.$ less $\left.T_{s}+T_{G 2}\right)$ was $46 \mathrm{hr}$. Since there was considerably greater variability in the $T_{c}$ than in the $T_{s}$ or $T_{a 2}$ (Fig. 7), it is apparent that this calculated $T_{G 1}$ is highly variable and accounts for most of the variability in the $T_{c}$.

Generation time $\left(T_{0}\right)$. The generation time $\left(T_{c}\right)$ is important in projecting chemotherapy studies and for use in calculating other cytokinetic parameters. Unfortunately, approaches to determining the $T_{c}$ involve indirection and assumptions. Therefore, we attempted to determine the $T_{c}$ utilizing several techniques.

(a) Analysis of the per cent labeled mitosis curves failed to reveal evidence for a second wave of labeled mitoses. By computer fitting to the per cent labeled mitosis curve, a generation time of 3 days with a wide variability was found (Fig. 7) (24). This technique for determining the $T_{\mathrm{c}}$ is probably the most accurate and least subject to bias in heterogeneous cell populations.

(b) The decrease in grain count per labeled cell after pulse labeling was exponential, and the half-time was 7-9 days in patients L. L. and E. H. (Figs. 2 and 3). In a relatively homogeneous population of cells, all of which are proliferating, the grain count half-time would be a precise measurement of $T_{c}$. However, if there are variations in cell cycle time, if cells enter a nonproliferating compartment, or if there is loss of cells below a labeling threshold, the grain count half-time overestimates the $T_{c}$. This may be shown as follows.

Let $\mathrm{n}$ cells be labeled by a single injection of tritiated thymidine, and let their mean grain count be $2 \mathrm{~g}$. Any cell loss is assumed to be random. If the durations of the $\mathrm{S}$ and $\mathrm{G}_{2}$-phases $\left(\mathrm{T}_{\mathrm{s}}, \mathrm{T}_{2}\right)$ are relatively constant, all of the labeled cells will have divided in time $T_{s}+T_{2}$ and the mean grain count will be $\mathrm{g}$. This initial component of the grain-halving curve is clearly seen in Figs. 2 and 3 , and is consistent with $\mathrm{T}_{\mathrm{s}}+\mathrm{T}_{2}=1.0-1.5$ days.

Of the $\mathrm{n}$ new cells produced at the first postlabeling division $\mathrm{n} \times \mathrm{GF}$ must reenter cycle if the growth fraction (GF) is to remain constant (28). Thus there are: $\mathrm{n}(1+\mathrm{GF})$ labeled cells reentering cycle $(\mathrm{n} \times \mathrm{GF}$ new cells, and $n$ cells to replace those that entered mitosis) ; and $\mathrm{n}(1-\mathrm{GF})$ labeled cells that leave cycle.

Let $T_{c}$ be the median cell cycle time. At time $t=T_{c}+\frac{1}{2} T_{s}+T_{2}$ after labeling, half of the cells of 
population (A) will have reentered mitosis. At this time there will be

$$
\begin{gathered}
2 \times \frac{1}{2} \mathrm{n}(1+\mathrm{GF}) \text { cells with mean grain count } \frac{1}{2} \mathrm{~g} \\
\text { (population A, binary fission) } \\
\frac{1}{2} \mathrm{n}(1+\mathrm{GF}) \text { cells with mean grain count } \mathrm{g} \\
\text { (population A, not yet divided) } \\
\mathrm{n}(1-\mathrm{GF}) \text { cells with mean grain count } \mathrm{g} \\
\text { (population B) }
\end{gathered}
$$

Thus, the mean grain count at this time is:

$$
\mathrm{g} \frac{\frac{1}{2}(1+\mathrm{GF})+\frac{1}{2}(1+\mathrm{GF})+(1-\mathrm{GF})}{(1+\mathrm{GF})+\frac{1}{2}(1+\mathrm{GF})+(1-\mathrm{GF})}
$$

which is equal to

$$
\text { g } \frac{4}{5+G F}
$$

Thus, the grain halving curve has a second component which would decrease by a factor $\frac{4}{5+G F}$ in time $\mathrm{T}_{\mathrm{c}}-\frac{1}{2} \mathrm{~T}_{\mathrm{s}}$. If the GF is small (approximately 20\%) as it is here, the $T_{c}$ for patient L. L. (Fig. 2) is about 3.0 days and for patient E. H. (Fig. 3 ) about 4.0 days.

It has been pointed out that loss of labeled cells below a labeling threshold (29) can also lead to an overestimate of $T_{e}$, and that a correction to the grain-halving curve should be applied. However, loss of labeled cells below a labeling threshold did not occur until at least 4 days after thymidine injection in patient L. L. (Fig. 2) or until 8 days in patient E. H. (Fig. 3). This effect should therefore lead to only small errors in the present estimates of $T_{\text {c }}$.

(c) The increase in grain count during continuous administration of $\mathrm{TdR}-{ }^{3} \mathrm{H}$ (Figs. 5 and 6 ) would provide a technique for determining the $T_{c}$ in homogeneous cell systems. However, the variability in $T_{c}$, the low $\mathrm{GF}$ and the considerable cell loss (see below) preclude interpretation of grain count increase.

(d) With continuous or intermittent tritiated thymidine administration, there occurs a linear increase in the labeling index for 8-9 days following which the per cent labeled cells leveled off. This break in the curve with continuous infusion of tritiated thymidine probably represented the maximum $T_{\mathrm{c}}$. The computer technique was employed to determine the set of kinetic factors which would fit most closely the labeling index with continuous labeling (29) (Fig. 5). It was found that an assumed uniform $T_{c}$ of 9 days and a growth fraction (GF) of $40 \%$ fit the curve reasonably well but is inappropriate since the $T_{c}$ is known to be highly variable. A 3 day generation time with wide variability as determined above by the per cent labeled mitosis curve and a GF of $20-30 \%$ also fit the observed labeling index curve and is consistent with the $T_{c}$ as calculated from the labeled mitosis curve.

It is concluded that the median $T_{c}$ is $3-4$ days with considerable variability.

Growth fraction. (a) If $100 \%$ of the cells were proliferating, the expected labeling index after pulse labeling would equal $\lambda T_{s} / T_{c}$ where $\lambda$ is a factor close to one (28). The growth fraction may be obtained by comparing this expected labeling index with that measured experimentally. Thus, the growth fraction is approximately

$\frac{L I}{T_{s} / T_{c}}$ or $\frac{L I \times T_{c}}{T_{s}}$. Using this formula, the growth fractions for L. L. and E. H. were estimated to be $21 \%$ and $15 \%$ respectively.

(b) A more sensitive extension of the above method of measuring growth fraction involves intermittent or continuous labeling with tritiated thymidine. This was done in patients T. J. and M. S. (Figs. 5 and 6). Since the intermittent labeling at 24 -hr intervals probably did not label all cells which entered the S-phase in patient T. J. it was not employed in determining growth fraction. For patient M. S., the method of Steel, Adams, and Barrett (28) was used. Theoretical continuous labeling curves were derived for various values of growth fraction by assuming the distributions of phase times corresponding to the computed labeled mitoses curve of Fig. 4. An acceptable fit to the data was obtained for a growth fraction of $20 \%$ (Fig. 6).

(c) The growth fraction may also be determined from the ratio of per cent labeled cells to per cent labeled mitoses at 4-5 days after pulse labeling $(30,31)$. This ratio was $45 \%$ for patient L. L. and $35 \%$ for patient E. H. However, this ratio is an overestimate of the growth fraction in a growing cell population, and a correction should be made for movement of cells from proliferating to nonproliferating compartments as described by Mendelsohn (31). Unfortunately, insufficient data were obtained in the present study to apply an exact correction. Moreover the corrected values would probably not be inconsistent with those determined by the above methods.

Thus, the growth fraction for these relatively small tumors (less than $1 \mathrm{~cm}$ in diameter), is approximately $20-30 \%$. There is evidence from experimental in vivo studies of solid tumors that the growth fraction is less in the center of large tumors. Our observation that the labeling index is lower in the center of large tumors than at the periphery of such tumors or in smaller tumors is consistent with this observation (Table II).

The distinction between the nonproliferating cells and cells with long generation times may be arbitrary. While some of the nonproliferating cells are end stage, many are probably capable of reentering the proliferatvie pool. 
Thus, in human acute leukemia small "resting" leukemia cells are capable of reverting to the proliferative state (32). In experimental systems nonproliferating tumor cells may be clonogenic. Also, in experimental systems, the growth fraction tends to decrease as the tumor size increases (33). Conversely, as a tumor is reduced in size by treatment the growth fraction may increase, that is, nonproliferating cells may reenter the proliferating pool.

Cell loss. It has been observed for animal and human tumors that the generation time and the growth fraction frequently results in a calculated or potential tumor volume doubling time $\left(\mathrm{DT}_{\mathrm{p}}\right)$ which is much shorter than the actual volume doubling time $\left(\mathrm{DT}_{\mathrm{a}}\right)(8,34)$. To explain this discrepancy, Steel has proposed cell loss (CL) by exfoliation, metastases, or cell death (34). If cell loss is assumed to be random with respect to the cell cycle, it may be calculated as a fraction of the rate of entry of cells into mitosis from the following equations (34).

$$
\begin{aligned}
& \text { (a) } \mathrm{CL}=1-\frac{\mathrm{DT}_{\mathrm{p}}}{\mathrm{DT}_{\mathrm{a}}} \\
& \text { (b) } \mathrm{DT}_{\mathrm{p}}=\mathrm{T}_{\mathrm{c}} \frac{\log 2}{\log (1+\mathrm{GF})}
\end{aligned}
$$

As determined above the $T_{c}$ is about 3 days and the GF about $20 \%$. Therefore, the $\mathrm{DT}_{\mathrm{p}}$ is about 12 days. The actual doubling time in our patients was impossible to determine because of the small size of the tumors and because the patients were not observed for a long time period in the untreated state. Sequential studies of the volume change of pulmonary metastases in patients with melanoma have indicated volume doubling times of 2-16 wk with a median of $6 \mathrm{wk}$ (27). So calculated, the rate of cell loss expressed as a fraction of the rate at which cells are added to the population by mitosis is $70 \%$. Thus, cell loss is a significant factor in determining growth rate in these relatively small tumors. In experimental solid tumors, the rate of cell loss increases as the tumor size increases $(33,35)$.

Did the $\beta$-irradiation alter the cytogenetics? The calculated maximum dose to the nucleus of the melanoma cells in our patients was $15 \mathrm{rad}(36)$. The fact that there was no change in the mitotic index after tritiated thymidine (Figs. 2, 4, and 5) would suggest that this amount of $\beta$-irradiation did not alter the cytokinetics of the tumor cells. The only slight and equivocal evidence that radiation may have altered the cytokinetics in this study was the grain count half-time which was slightly lower in the more heavily labeled cells (Figs. 2 and 3 ).

\section{REFERENCES}

1. Taylor, P. H., P. S. Woods, and W. L. Hughes. 1957. The organization and duplication of chromosomes as revealed by autoradiographic studies using tritium labeled thymidine. Proc. Nat. Acad. Sci. U. S. A. 43: 122.

2. Johnson, H. A., J. R. Rubini, E. P. Cronkite, and V. P. Bond. 1960. Labeling of human tumor cells in vivo by tritiated thymidine. Lab. Invest. 9: 460.

3. Johnson, H. A., W. E. Haymaker, J. R. Rubini, T. M. Fliedner, V. P. Bond, E. P. Cronkite, and W. L. Hughes. 1960. A radioautographic study of a human brain and glioblastoma multiforme after the in vivo uptake of tritiated thymidine. Cancer. 13: 636.

4. Baserga, R., G. C. Henegar, W. E. Kisielski, and H. Lisco. 1962. Uptake of tritiated thymidine by human tumors in vivo. Lab. Invest. 11: 360.

5. Chone, B. and H. J. Trischbier. 1962. In vivo studies with Thymidine- ${ }^{3} \mathrm{H}$ bei portoneale Karzinase. I. Nuclearmedizin. 2: 240 .

6. Clarkson, B., K. Ota, T. Ohkita, and A. O'Conner. 1965 Kinetics of proliferation of cancer cells in neoplastic effusions in man. Cancer. 18: 1189.

7. Hoffman, J., and J. Post. 1967. In vivo studies of DNA synthesis in human normal and tumor cells. Cancer Res. 27: 898.

8. Frindel, E., E. Malaise, and M. Tubiana. 1968. Cell proliferation kinetics in five human solid tumors. Cancer. 22: 611 .

9. Bennington, J. L. 1969. Cellular kinetics of invasive squamous carcinoma of the human cervix. Cancer Res. 29: 1082.

10. Schabel, F. M., Jr., H. E. Skipper, M. Trader, and W. S. Wilcox. 1965. Experimental evaluation of potential anticancer agents. XIX. Sensitivity of nondividing leukemic cell populations to certain classes of drugs in vivo. Cancer Chemother. Rep. 48: 17.

11. Bruce, W. R., and F. A. Valeriote. 1968. Normal and malignant stem cells and chemotherapy. In Proliferation and Spread of Neoplastic Cells. M. D. Anderson Hospital Symposium, The Williams \& Wilkins Company, Baltimore. 409

12. Frei, E., III, and E. Freireich. 1965. Progress and perspectives in the chemotherapy of acute leukemia. Advanc. Chemother. 2: 269.

13. Freireich, E., E. S. Henderson, M. R. Karon, and E. Frei, III. 1968. The treatment of acute leukemia considered with respect to cell population kinetics. In Proliferation and Spread of Neoplastic Cells. M. D. Anderson Hospital Symposium, The Williams \& Wilkins Company, Baltimore. 441.

14. Skipper, H. E., F. M. Schabel, Jr., and W. S. Wilcox. 1964. Experimental evaluation of potential anticancer agents. XIII. On the criteria and kinetics associated with "curability" of experimental leukemia. Cancer Chemother. Rep. 35: 1 .

15. Skipper, H. E., F. M. Schabel, Jr., and W. S. Wilcox. 1967. Experimental evaluation of potential anticancer agents. XXI. Scheduling of arabinosylcytosine to take advantage of its S-phase specificity against leukemia cells. Cancer. Chemother. Rep. 51: 125.

16. Luce, J. K., and W. G. Thurman. 1969. Imidazole carboxamide triazeno (ICT) treatment of solid tumors. Proc. Amer. Ass. Cancer Res. 10: 53. (Abstr.)

17. Caro, L. G. 1964. High-resolution autoradiography. In Methods in Cell Physiology. D. M. Prescott, editor. Academic Press Inc., New York I: 327.

18. Schmidt, G., and S. J. Thannhauser. 1945. A method for the determination of deoxyribonucleic acid, ribonucleic acid, and phosphoproteins in animal tissues. J. Biol. Chem. $161: 83$. 
19. Schneider, W. C. 1957. Determination of nucleic acids in tissues by pentose analysis. In Methods in Enzymology. C. Kaplan, editor. Academic Press Inc., New York. III: 680 .

20. Quastler, H., and F. G. Sherman. 1959. Cell population kinetics in the intestinal epithelium of the mouse. Exp. Cell. Res. 17: 420 .

21. Wimber, D. E. 1963. Methods for studying cell proliferation with emphasis on DNA labels. In Cell Proliferation. L. F. Lamerton and R. J. M. Frey, editors. Blackwell Scientific Publications Ltd., Oxford. 1.

22. Baserga, R. 1965. The relationship of the cell cycle to tumor growth and control of cell division: a review. Cancer Res. 25: 581.

23. Killmann, S. A., E. P. Cronkite, J. S. Robertson, T. M. Fliedner, and V. P. Bond. 1963. Estimation of phases of the life cycle of leukemic cells from labeling in human beings in vivo with tritiated thymidine. Lab. Invest. 12: 671 .

24. Barrett, J. C. 1966. A mathematical model of the mitotic cycle and its application to the interpretation of percentage labeled mitoses data. J. Nat. Cancer Inst. 37: 443.

25. Wolf-Jurgenson, P., A. W. Kopf, G. Lipkin, and R. S. Bart. 1968. Influence of anti-lymphocytic serum on malignant melanoma. J. Invest. Dermatol. 51: 441.

26. DeCosse, J. J., and S. Gelfant. 1968. Noncycling tumor cells mitogenic response to antilymphocytic serum. Science (Washington). 162: 698.

27. Nathanson, L., T. C. Hall, G. F. Vawter, and S. Farber.
1967. Melanoma as a medical problem. Arch. Intern. Med. 119: 479.

28. Steel, G. G., K. Adams, and J. C. Barrett. 1966. Analysis of the cell population kinetics of transplanted tumours of widely-differing growth rate. Brit. J. Cancer. 20: 784.

29. Fried, J. 1969. Correction for threshold error in the determination of generation time by the grain-count halving method. J. Theor. Biol. 24: 108.

30. Mendelsohn, M. L. 1963. Cell proliferation and tumor growth. In Cell Proliferation. L. F. Lamerton and R. J. M. Frey, editors. Blackwell Scientific Publications Ltd., Oxford. 190.

31. Mendelsohn, M. L. 19б2. Autoradiographic analysis of cell proliferation in spontaneous breast cancer of $\mathrm{C} 3 \mathrm{H}$ mouse. III. The growth fraction. J. Nat. Cancer Inst. 28: 1015.

32. Saunders, E. F., and A. M. Mauer. 1969. Reentry of nondividing leukemic cells into a proliferative phase in acute childhood leukemia. J. Clin. Invest. 48: 1299

33. Frindel, E., E. P. Malaise, E. Alpen, and M. Tubiana. 1967. Kinetics of cell proliferation of an experimental tumor. Cancer Res. 27: 1122.

34. Steel, G. G. 1967. Cell loss as a factor in the growth rate of human tumors. Eur. J. Cancer. 3: 381.

35. Tannock, I. F. 1969. A comparison of cell proliferation parameters in solid and ascites Ehrlich tumors. Cancer Res. 29: 1527

36. Dewey, W. C., R. M. Humphrey, and B. A. Jones. 1965 Comparisons of tritiated thymidine, tritiated water and cobalt-60 gamma rays inducing chromosomal aberrations. Radiat. Res. 24: 214. 